\title{
The International Congress of Psychology (ICP 20 I2): a brief analysis of the scientific programme
}

\author{
Anthony L Pillay', Basil J Pillay' and Norman Duncan²
}

\author{
'Department of Behavioural Medicine, University of KwaZulu-Natal, South Africa \\ ${ }^{2}$ Faculty of Humanities, University of Pretoria, South Africa \\ Corresponding author: \\ Anthony L Pillay, Fort Napier Hospital, P O Box 370, Pietermaritzburg 3200, South Africa. \\ Email: anthony.pillay@kznhealth.gov.za
}

\begin{abstract}
South African Psychology has a unique history and stands out among its peers across the world. In the wake of its divided past and collusion with apartheid, its subsequent international 'rehabilitation' was capped by its successful hosting of the International Congress of Psychology (20I2) during July 20I2. This was the first such event on the African continent, and involved a mammoth organisational effort that spanned more than 6 years. This article briefly analyses the scientific programme within the context of the content areas and the countries represented. Some of the challenges faced by the Scientific Committee are also outlined, together with the strategies developed to manage these challenges.
\end{abstract}

\section{Keywords}

Congress, continuing education, psychologist, psychology

South African Psychology has a complex history, a mixed bag that included a period of decidedly dubious practices, especially in the context of apartheid and the preceding political era that was also characterised by institutionalised racial oppression and systematic discrimination against large sectors of the South African population. The discipline's reputation had been substantially marred by its association with these regimes in the many decades before the country achieved democracy and international recognition.

Much has been written about the extent to which psychology responded to and collaborated with the social engineering and human rights violations of the pre-1994 era, as well as the psycho-logical impact of these processes on the country's majority (cf. Nicholas \& Cooper, 1990). 
Psychology's failure to use its vast theoretical and scientific resources for the betterment of the living conditions and quality of life of all its citizens has been highlighted and lamented (Dawes, 1985; Seedat, 1997).

While psychology emerged as a field of study in South Africa during the second decade of the 20th century, was taught at tertiary institutions from the 1920s onward, and practised in clinical, educational, industrial, and other settings for the better part of the previous century, the discipline struggled to find legitimacy until the 1990s. This was largely due to its complicity with apartheid through its academic and professional practices (such as providing racially segregated teaching and training, as well as academic legitimation for apartheid) (Manganyi, 2013). Its attempts to actively promote the ideology of White supremacy through psychological 'research' have been widely documented. History is replete with examples of poorly applied science providing support for spurious ideas such as the superiority of one racialised group over another. The work of Fick (1939) was one such South African example of psychological 'research' used to support racist notions of cognitive differences among racial groups, not unlike the infamous works of Jensen (1969) and others elsewhere in the world. Recently, Saths Cooper noted that during his incarceration on the Robben Island prison in the late 1970s, together with Nelson Mandela and others, he encountered an unusually large number of psychologists among their captors (Pather, 2014).

However, there has also been a positive side to South African Psychology in the earlier years. The country provided the world with a number of psychologists who went on to become pioneers in their respective areas of psychological theory and research, making significant contributions to the development of the field internationally. These included Joseph Wolpe, Arnold Lazarus, and Stanley Rachman, among others (Antony, 2013). The groundbreaking works produced by these individuals had germinated in the course of their training and work in South Africa. Nicholas (2013) also noted several other early South African engagements with international psychology. Of note, in 2012, the South African psychologist Saths Cooper was elected President of the International Union of Psychological Science (IUPsyS). All of these examples serve to illustrate the extent of South Africa's contribution to international psychology and thinking in the broader area of human behaviour and development.

Evidence of South Africa's contribution to psychology internationally is also to be found in the number of psychologists who have left the country to ply their trade elsewhere in the world. Locally trained professional psychologists have been welcomed and even actively recruited in large numbers by countries such as the United Kingdom, Australia, Ireland, and others (Pillay \& Kramers, 2003). Evidently, South African Psychology is doing something right (and something that is much sought after by many high-income countries). However, it should also be noted that this trend discernible within the psychology community for psychologists to emigrate once they have qualified, has negative consequences. Recent statistics reveal that currently, South Africa has approximately one psychologist per 14,000 people (Duncan, Frank, \& Stevens, 2007). The constant flight of psychologists trained in South Africa to higher income countries means that this unfavourable ratio will not improve significantly in the short-term, unless of course the loss of South African trained psychologists to higher income countries is offset by the immigration of psychologists from higher income countries to South Africa, which is not very likely.

Over the years, South African psychology has developed substantially in the academic, research, and practice arenas. The discipline has rapidly gained popularity as a course of study at universities, and is currently one of the more popular undergraduate courses of study (Council on Higher Education, 2010). This is not simply a local phenomenon when considering that The Princeton Review (2014) recently listed psychology as one of the top 10 university (undergraduate) majors in the United States, as well. Even at postgraduate level, there is stiff competition for places at all of the country's universities offering professional psychology training, which is an indication of the 
value attributed to psychology as a career. This augurs well for the further development and progression of the field in South Africa.

It is clear that psychology in South Africa is alive and well at the start of the 21 st century. Despite the many obstacles confronting it, including the continued under-representation of people of colour in the profession of psychology, the ongoing racialised trends in research and publications and the loss of locally qualified psychologists to high-income countries (Pillay \& Kramers, 2003), there is adequate reason to believe that the future looks bright for the discipline and profession. There is also evidence that it has much to contribute to international psychology.

Of course, it is argued that the discipline should be offering more to the South African community, given the oppressive history and emotional effects of chronic discrimination and maltreatment, and psychology's capacity to improve the human condition (Nicholas \& Cooper, 1990).

Against this background, the authors reflect briefly on the 30th International Congress of Psychology (ICP), held in Cape Town, from 22 to 27 July 2012. They present the results of a cursory examination of the scientific programme, especially the content areas and the countries represented. The event was organised and hosted by the Psychological Society of South Africa (PsySSA), with the support of the National Research Foundation (NRF), under the auspices of the IUPsyS.

\section{Background and context}

The ICP is a quadrennial scientific event that has been hosted by many different countries over the course of its history, since the inaugural congress in Paris in 1889 (IUPsyS, 2013). While the event seeks to bring together psychologists from all parts of the world, throughout its history, it was held largely in high-income countries, with the African continent never featuring, until the ICP 2012 in Cape Town, South Africa. The bid to host the event was won by the PsySSA as the organisation representing South African Psychology, and the organising committee spent over 6 years planning and laying the ground for hosting the Congress. The early start was made to ensure a high-quality event. Among the various working committees and task groups, the Scientific Committee was one of the key organising structures of the Congress.

In addition to the standard academic presentations and workshop formats, the ICP 2012 also organised a series of controversial debates and an Emerging Psychologists' Programme that selected newly graduated psychology scholars from around the world to participate in a structured series of workshops and events aimed at furthering their academic and research skills and careers.

The establishment and constitution of the ICP 2012 Scientific Committee were informed by multiple considerations, including (1) the need for scientific rigour; (2) the showcasing of South African and African Psychology; (3) addressing succession planning through the inclusion of emerging scholars, since those at the helm of the discipline are a steadily ageing cohort; and (4) as a means of pushing the frontiers of psychology by ensuring that previously un- or underrepresented fields of psychology (such as Critical Psychology and the Psychology of Racism) could utilise the ICP 2012 as an impetus for growth.

Consisting of psychology scholars from around the country, and elsewhere in the world, the Scientific Committee was chaired by the academic and PsySSA Past President, Norman Duncan. Working with software developers, the committee tailored a customised online system for the submission, review, and management of abstracts. Among the first duties of the Scientific Committee was to decide on the specialised content areas and the formation of Congress tracks. A total of 44 divisions were established (e.g., Cognitive, Educational, Experimental, Industrial/Organisational/ Work, and Clinical Psychology). A considerable effort was also made to given appropriate attention to various still-embryonic sub-fields of psychology (e.g., Liberation Psychology) in the establishment of the scientific committee divisions. Another priority was the peer review process which 
serves to ensure stringent academic standards in the Congress's scientific programme. Developing a rigorous peer review process is critical in the dissemination of academic material, with reviewers providing 'an essential control' that enhances the end product (Ross, Hankerson, Irwin, Stone, \& Higley, 2007).

The volume of abstracts received (approximately 10,000) posed a major challenge in terms of the handling, distribution, referring, and processing of abstracts and the need for an efficient online abstract management system was evident early on in the process. Consequently, the ICP 2012 Organising Committee took the decision to commission the development of a customised abstract management system, tailored to comprehensively address all of the Congress requirements. In addition to the standard double-blind review process, the Scientific Committee instituted an unusual feature (relative to previous congresses), by way of a quality assurance phase in the review process. A small quality assurance team provided a third level of review (after the reviewers and the division chairs) by examining all accepted abstracts to confirm suitability. Thereafter, abstracts requiring minor language editing were handled by a specialist editing team.

The programme for the ICP 2012 was a multifaceted one. In addition to the standard papers, posters and workshop presentations, it included an impressive complement of keynote addresses and State-of-the-Science lectures by a significant number of eminent researchers, including Michael Rutter and Elizabeth Loftus. Furthermore, the programme included numerous invited papers, workshops and symposia, controversial debates, and other innovative formats. Therefore, developing the programme presented significant challenges, which required intricate planning and positioning. With close to 4500 presentations in total, scheduled to take place over 5 days, over 20 parallel sessions had to be developed. This had an obvious spill-over in terms of logistics and venue allocation for the different sessions. Considering the difficulty in predicting the numbers of delegates who would attend specific sessions or papers throughout the Congress, there was an understandable over-demand at a few venues. However, within the magnitude of the event this problem occurred in only a few venues, and was addressed by the organising committee, by way of venue changes.

\section{The ICP 2012 presentations: An analysis}

The following data and discussion represent a summary and cursory analysis of the academic presentations. It is not meant to be a comprehensive investigation of the Congress presentations. For the purpose of the current analysis, all of the ICP 2012 abstracts were examined in terms of their content area, the presenters' country of origin, and, where available, the developmental focus of the presentation, for example, child/adolescent or adult. In examining content areas, keywords, phrases, or ideas in the abstract were analysed, and the variables or psychological areas referred to most were used to infer the dominant content area. Therefore, this classification should not be considered in absolute terms, but rather as broad focus areas.

The review process resulted in a rejection rate of $30 \%$, which was higher than in previous ICP congresses, and perhaps indicative of the rigour inherent in the multiple levels of screening and review that were instituted. The accepted papers (oral and poster presentations), workshops, and invited presentations at the ICP 2012 are summarised below, reflecting distributions by country of origin and broad area of study.

Tables 1 and 2 illustrate the distribution of oral papers and poster presentations by country of origin and broad area of study. There were 16 invited addresses from the United States; 6 from Canada; 5 each from Germany, Netherlands, and South Africa; and 4 each from the United Kingdom, Argentina, and Australia. About one-third of the invited addresses were from low- and middle-income countries. The dominant content areas of the invited addresses were (in descending 
Table I. Submitted papers and posters by country.

\begin{tabular}{|c|c|c|c|c|}
\hline \multirow[t]{2}{*}{ Country } & \multicolumn{2}{|c|}{ Papers } & \multicolumn{2}{|c|}{ Posters } \\
\hline & $N$ & $\%$ & $n$ & $\%$ \\
\hline South Africa & 569 & 25.5 & 216 & 18.1 \\
\hline China & 360 & 16.1 & 142 & 11.9 \\
\hline India & 139 & 6.2 & 27 & 2.3 \\
\hline Iran & 117 & 5.2 & 104 & 8.7 \\
\hline United States & 115 & 5.2 & 67 & 5.6 \\
\hline Germany & 105 & 4.7 & 35 & 2.9 \\
\hline Australia & 68 & 3.0 & 14 & 1.2 \\
\hline Brazil & 51 & 2.3 & 48 & 4.0 \\
\hline United Kingdom & 38 & 1.7 & 7 & 0.6 \\
\hline Russian Federation & 38 & 1.7 & 17 & 1.4 \\
\hline Canada & 38 & 1.7 & 22 & 1.8 \\
\hline The Netherlands & 35 & 1.6 & 7 & 0.6 \\
\hline Spain & 35 & 1.6 & 61 & 5.1 \\
\hline Nigeria & 28 & 1.3 & 14 & 1.2 \\
\hline Turkey & 28 & 1.3 & 8 & 0.7 \\
\hline Japan & 28 & 1.3 & 94 & 7.9 \\
\hline Other & $44 I$ & 19.7 & 311 & 26.0 \\
\hline$N$ & 2233 & 100 & 1194 & 100 \\
\hline
\end{tabular}

Table 2. Papers and posters by area of study.

\begin{tabular}{|c|c|c|c|c|}
\hline \multirow[t]{2}{*}{ Area } & \multicolumn{2}{|c|}{ Papers } & \multicolumn{2}{|c|}{ Posters } \\
\hline & $N$ & $\%$ & $n$ & $\%$ \\
\hline Industrial/Organisational/Work Psychology & 258 & 11.6 & 118 & 9.9 \\
\hline Clinical Psychology & 182 & 8.2 & 126 & 10.6 \\
\hline Educational Psychology & 158 & 7.1 & 66 & 5.5 \\
\hline Developmental Psychology & 124 & 5.6 & 75 & 6.3 \\
\hline Social Psychology & 116 & 5.2 & 102 & 8.5 \\
\hline Assessment and Evaluation & 116 & 5.2 & 72 & 6.0 \\
\hline Cognitive Psychology & 106 & 4.7 & 64 & 5.4 \\
\hline Health Psychology & 102 & 4.6 & 53 & 4.4 \\
\hline Positive Psychology & 80 & 3.6 & 50 & 4.2 \\
\hline Counselling & 79 & 3.5 & 41 & 3.4 \\
\hline Culture & 68 & 3.0 & 37 & 3.1 \\
\hline Trauma & 62 & 2.8 & 21 & 1.8 \\
\hline Personality & 58 & 2.6 & 39 & 3.3 \\
\hline General & 57 & 2.6 & 36 & 3.0 \\
\hline Neuropsychology & 49 & 2.2 & 16 & 1.3 \\
\hline Sexuality & 48 & 2.1 & 12 & 1.0 \\
\hline Community Psychology & 42 & 1.9 & 33 & 2.8 \\
\hline HIVIAIDS & 38 & 1.7 & 16 & 1.3 \\
\hline Other & 490 & 21.9 & 217 & 18.2 \\
\hline$N$ & 2233 & 100 & 1194 & 100 \\
\hline
\end{tabular}


Table 3. Invited symposia papers by country.

\begin{tabular}{lrr}
\hline Country & $n$ & $\%$ \\
\hline South Africa & 58 & 21.4 \\
United States & 54 & 19.9 \\
Canada & 16 & 5.9 \\
Germany & 13 & 4.8 \\
Italy & 13 & 4.8 \\
India & 11 & 4.1 \\
France & 10 & 3.7 \\
The Netherlands & 10 & 3.7 \\
United Kingdom & 10 & 3.7 \\
Australia & 9 & 3.3 \\
Uganda & 7 & 2.6 \\
Argentina & 7 & 2.6 \\
Japan & 6 & 2.2 \\
Russian Federation & 5 & 1.8 \\
Other & 42 & 15.5 \\
$N$ & 271 & 100
\end{tabular}

order of prominence): Culture, Health, Neuropsychology, Social, Cognitive, Educational, and Developmental Psychology, among others.

Tables 3 and 4 show the country and area of study distributions for the invited symposia papers, while Tables 5 and 6 reflect the distribution of submitted symposia papers, by country and area of study. In the current analysis, the symposium papers were counted individually. An examination of the total number of submitted poster and oral presentations revealed that Congress participants from South Africa provided 985 (22.6\%) of the presentations, followed by China with $529(12.1 \%)$, United States with 430 (9.9\%), Iran with 222 (5.1\%), and India with $186(4.3 \%)$ presentations. The content areas that dominated overall were (in descending order of prominence) as follows: Industrial/Organisational/Work, Clinical, Developmental, Educational, Social Psychology, Assessment and Evaluation, and Cognitive Psychology.

Table 7 shows the distribution of the total complement of posters and papers by continent, and the major contributors per continent. The programme included 42 electronic posters, of which 32 were from the United States. Table 8 indicates the breakdown of posters, papers, and submitted symposia papers by focus or research participants' developmental level.

\section{Reflections on the ICP 2012 presentations}

The finding that just over one-quarter of the oral papers was from South Africa is not completely surprising, considering the conference was held in this country. Nevertheless, it is an encouraging statistic. Although largely anecdotal, feedback from reviewers and the Scientific Committee indicated a high level of satisfaction with the quality of abstracts and the work reflected in the abstracts submitted from South Africa. In total, almost 1000 (of the nearly 4000) papers and posters were presented by the host country's psychology community, which can be considered fairly impressive, considering the country's relatively recent re-entry into the international fold, and the fact that approximately 110 countries were represented at the Congress.

The relatively high proportion of papers from China and India must be understood against the populations of these countries, which together constitute $36.8 \%$ of the world's total population 
Table 4. Invited symposia papers by area of study.

\begin{tabular}{lrr}
\hline Area & $n$ & $\%$ \\
\hline Cognitive Psychology & 32 & 11.8 \\
Aviation Psychology & 20 & 7.4 \\
Educational Psychology & 17 & 6.3 \\
Health Psychology & 17 & 6.3 \\
Trauma & 16 & 5.9 \\
Developmental Psychology & 16 & 5.9 \\
Social Psychology & 15 & 5.5 \\
Neuropsychology & 14 & 5.2 \\
Counselling & 13 & 4.8 \\
Professional Training and Licensure & 11 & 4.1 \\
Environment/Sustainability & 11 & 4.1 \\
General & 9 & 3.3 \\
Assessment and Evaluation & 8 & 3.0 \\
Industrial/Organisational/Work Psychology & 8 & 3.0 \\
Culture & 7 & 2.6 \\
History of Psychology & 7 & 2.6 \\
Psychopharmacology & 6 & 2.2 \\
Other & 44 & 16.2 \\
$N$ & $27 I$ & 100
\end{tabular}

Table 5. Submitted symposia papers by country.

\begin{tabular}{lrr}
\hline Country & $n$ & $\%$ \\
\hline United States & 216 & 24.5 \\
South Africa & 200 & 22.7 \\
Australia & 53 & 6.0 \\
Germany & 45 & 5.1 \\
United Kingdom & 40 & 4.5 \\
Canada & 34 & 3.9 \\
China & 27 & 3.1 \\
Netherlands & 21 & 2.4 \\
India & 20 & 2.3 \\
Italy & 15 & 1.7 \\
Russian Federation & 15 & 1.7 \\
Brazil & 14 & 1.6 \\
Norway & 12 & 1.4 \\
$N$ & 880 & 100
\end{tabular}

(World Population Statistics, 2013). While one might have expected that countries from North America and Europe would dominate the paper presentations, this was not the case. There are at least two possible explanations for this. First, in recent years, there has been a trend towards more poster presentations at international congresses. Second, researchers from high-income countries are increasingly opting to organise symposia with colleagues and other researchers in their areas of specialisation. This is indeed evident in the symposia presented at the Congress, where five of the 
Table 6. Submitted symposia papers by area of study.

\begin{tabular}{lcr}
\hline Area & $n$ & $\%$ \\
\hline Clinical & $7 I$ & 8.1 \\
Developmental & 64 & 7.3 \\
Assessment and Evaluation & 53 & 6.0 \\
Industrial/Organisational/Work Psychology & 47 & 5.3 \\
Cognitive Psychology & 45 & 5.1 \\
Teaching and Education in Psychology & 44 & 5.0 \\
Social Psychology & 38 & 4.3 \\
Culture & 35 & 4.0 \\
Community Psychology & 34 & 3.9 \\
General & 34 & 3.9 \\
Educational Psychology & 33 & 3.8 \\
Ethics & 31 & 3.5 \\
Social Issues and Political Psychology & 29 & 3.3 \\
Gender & 27 & 3.1 \\
Health Psychology & 25 & 2.8 \\
Professional Training and Licensure & 23 & 2.6 \\
Counselling & 23 & 2.6 \\
Positive Psychology & 21 & 2.4 \\
$N$ & 880 & 100.0
\end{tabular}

Table 7. Total submitted posters and papers by continent and major contributors per continent.

\begin{tabular}{lcclll}
\hline & \multicolumn{2}{c}{ Total posters and papers } & & \multicolumn{2}{c}{ Continent's major contributor } \\
\cline { 2 - 3 } & $n$ & & & Country & $\%$ \\
\hline North America & 607 & 14.0 & & United States & 70.8 \\
South America & 171 & 3.9 & & Brazil & 66.1 \\
Europe & 941 & 21.6 & & Germany & 19.6 \\
Africa & 1117 & 25.7 & & South Africa & 88.2 \\
Asia & 1359 & 31.2 & & China & 38.9 \\
Oceania & 144 & 3.1 & & Australia & 93.8 \\
Other/missing & 10 & 0.2 & & & \\
$N$ & 4349 & 100 & & &
\end{tabular}

top six countries were high-income countries, with the United States presenting $24.5 \%$ of the symposia.

Excluding the United States, the poster contributions were dominated by non-Anglophone countries. Considering that English was the official language of the Congress, this is understandable, since many presenters who are not proficient in the official conference language generally prefer using posters to convey their research findings. Japanese presenters, for example, presented 94 posters and 28 oral papers.

A total of 1194 poster presentations were made at ICP 2012, which represents approximately one-fifth of the total complement of presentations. This is a reflection of the trend over the years, from a time when posters were regarded as a sub-optimal medium for conference presentations, to 
Table 8. Posters, papers, and submitted symposia papers by focus or participants' developmental level.

\begin{tabular}{|c|c|c|c|c|c|c|}
\hline & \multicolumn{2}{|c|}{ Posters } & \multicolumn{2}{|c|}{ Papers } & \multicolumn{2}{|c|}{$\begin{array}{l}\text { Submitted } \\
\text { symposia papers }\end{array}$} \\
\hline & $n$ & $\%$ & $N$ & $\%$ & $n$ & $\%$ \\
\hline Adult & 445 & 37.3 & 644 & 28.8 & 108 & 12.3 \\
\hline Child/adolescent & 216 & 18.1 & 358 & 16.0 & 69 & 7.8 \\
\hline Mixed & 27 & 2.3 & 63 & 2.8 & 16 & 1.8 \\
\hline \multirow[t]{2}{*}{ Not applicable } & 506 & 42.4 & 1168 & 52.3 & 687 & 78.1 \\
\hline & 1194 & 100 & 2233 & 100 & 880 & 100 \\
\hline
\end{tabular}

the present day when posters are regarded as the ideal method of conveying compact research findings. Since the turn of the century, it is becoming increasingly clear that there are many good reasons to opt for poster presentations over oral presentations (Ross et al., 2007).

As expected, invited addresses and invited symposium papers from high-income countries dominated. Nevertheless, it was encouraging to see invited presentations also delivered, albeit in smaller numbers, by presenters from other countries, such as Argentina, Brazil, India, Cameroon, Sri Lanka, China, Egypt, Lebanon, Nigeria, Uganda, and South Africa. Of course, it should be noted that the under-representation of certain geographical regions was largely a result of the extent of the development of psychology across the world.

The overall low numbers of presentations from African countries other than South Africa is concerning, and it would have been expected that, given the Congress location, more African academics would have considered presenting their work. Cost issues constitute an obvious explanation. Nevertheless, a fair number of delegates from African countries outside of South Africa attended the ICP 2012. Perhaps the initiative towards establishing the Pan-African Psychology Union (PAPU) may serve to bolster scholarly developments and dissemination on broader platforms, especially considering the vision of a commitment to 'scholarship and human development in our communities, countries, Africa and the World' (South African Journal of Psychology: Editorial, 2013, p. 156).

An interesting observation is the country status disparity (World Bank, 2014) between submitted presentations (poster and oral papers) and invited symposia and addresses. Middle- and lowincome countries featured prominently among the submitted presentations, while high-income countries dominated all forms of invited presentations. The high number of submitted works is encouraging and may be explained by both the efforts of the ICP 2012 organisers in rallying middle- and low-income country academics, as well as globalisation trends (Prilleltensky, 2012) that are seeing scholars from poorer countries taking their place in international congresses. It is, therefore, hoped that in the near future, we will begin to see more invited presenters from middle- and low-income countries.

A positive finding was the significant number of presentations from Japan. This may relate to the fact that Japan will be hosting the next congress, that is, ICP 2016. This augurs well for a high level of interest from local academics and researchers when the event takes place on Japanese shores. Local support is vital in organising and hosting an event of this magnitude, as was evident at the ICP 2012, where South African psychologists attended and presented papers in large numbers.

A large number of papers $(n=1151)$ were presented in the context of symposia. As indicated, this is a relatively recent trend in international congresses, and may reflect the greater networking, and in some cases collaborative work across different contexts. It indicates the extent to which 
researchers have links with others in their area of work, compared to decades earlier when researchers tended to work in greater isolation. Of course, this could also be a function of the growing size of psychology conferences and the consequent need to streamline and focus congress programmes more tightly.

An examination of the content presented at the ICP 2012 revealed that Industrial/Organisational/ Work, Clinical, Developmental, Educational, Social, and Assessment and Evaluation Psychology were among the most prominent areas covered in the Congress through submitted papers and posters. It is important to note that many presentations contained overlapping content, but for the purpose of this analysis, the area or variable(s) most frequently or prominently referred to in the abstract were noted in this exploratory analysis. The content area analysis must therefore be viewed in this light, and not in absolute terms.

Interestingly, of those presentations that focused on specific developmental groups, considerably more addressed issues of adulthood than issues of childhood. While this could be a matter of concern since $26 \%$ of the world's population is under 15 years of age (United Nations, 2012), it is important that the present findings are viewed with the necessary caution. Although the ICP is the probably the largest international gathering of psychology academics and practitioners, the work presented at this conference represents a portion of the psychological research being done around the world.

\section{Conclusion}

The ICP 2012 has, by all accounts, proved an overwhelming success, especially considering the feedback from overseas delegates and those familiar with large international congresses. The wide distribution of countries represented at the Congress also attests to the interest in the event, and confidence among delegates from around the world to make the trip to South Africa, despite the negative reports the country sometimes receives in relation to tourist visits.

The finding that presenters represented a wide range of countries is encouraging, although there is concern that participation from middle-income and lower income countries needs to increase, so that psychology can more appropriately serve all the contexts in which it is taught, researched, and practised. The distribution of content areas presented at the Congress has been broad, and reflective of the multitude of sub-fields that currently characterise the discipline and profession of psychology. It was not surprising to note the specialisations that dominated the programme, considering the research interest in these areas in the global literature, and South Africa as well. However, the inclusion of previously under-represented tracks has been a progressive step, which will hopefully be sustained in future events. It is unfortunate that previous ICP congress data were not available for comparison, but it is hoped that the present analysis will prove useful for future events.

\section{Funding}

This research received no specific grant from any funding agency in the public, commercial, or not-for-profit sectors.

\section{References}

Antony, M. M. (2013). Behavior therapy. In D. Wedding \& R. Corsini (Eds.), Current psychotherapies (pp. 193-230). Belmont, CA: Brooks/Cole.

Council on Higher Education. (2010). 2010 higher education data: Graduates. Retrieved from http://www. che.ac.za/focus_areas/higher_education_data/2010/graduates

Dawes, A. (1985). Politics and mental health: The position of clinical psychology in South Africa. South African Journal of Psychology, 15, 55-61. 
Duncan, N., Frank, J., \& Stevens, G. (2007). Transforming South African professional and organised psychology: Examining our achievement thus far. Paper presented at the Annual South African Psychology Congress, Durban, August 28.

Fick, M. (1939). The educability of the South African native. Pretoria, South Africa: South African Council for Educational and Social Research.

International Union of Psychological Science (IUPsyS). (2013). History of the IUPsyS. Retrieved from http:// www.iupsys.net/about/history/

Jensen, A. R. (1969). How much can we boost IQ and scholastic achievement. Harvard Educational Review, $39,1-123$.

Manganyi, N. C. (2013). On becoming a psychologist in apartheid South Africa. South African Journal of Psychology, 43, 278-288.

Nicholas, L. (2013). Early South African engagement with international psychology. South African Journal of Psychology, 43, 289-299.

Nicholas, L., \& Cooper, S. (1990). Psychology and apartheid. Johannesburg, South Africa: Vision.

Pather, D. (2014). Cooper keen to change minds. Sunday Tribune, 26 January, 19.

Pillay, A. L., \& Kramers, A. L. (2003). South African clinical psychology, employment (in)equity and the 'Brain Drain'. South African Journal of Psychology, 33, 52-60.

Prilleltensky, I. (2012). The what, why, who, and how of globalization: What is Psychology to do? Journal of Social Issues, 68, 612-629.

The Princeton Review. (2014). Top 10 college majors. Retrieved from http://www.princetonreview.com/college/top-ten-majors.aspx

Ross, C., Hankerson, S., Irwin, M., Stone, A., \& Higley, D. (2007). Giving a good scientific presentation. Retrieved from https://www.asp.org/education/EffectivePresentations.pdf

Seedat, M. (1997). The quest for liberatory psychology. South African Journal of Psychology, 27, 261-270.

South African Journal of Psychology: Editorial. (2013). The Cape Town Declaration. South African Journal of Psychology, 43, 156.

United Nations. (2012). World population 2012. Retrieved from http://www.un.org/en/development/desa/ population/publications/pdf/trends/WPP2012_Wallchart.pdf

World Bank. (2014). How we classify countries. Retrieved from http://data.worldbank.org/about/countryclassifications

World Population Statistics. (2013). Countries. Retrieved from http://www.worldpopulationstatistics.com/ countries/ 